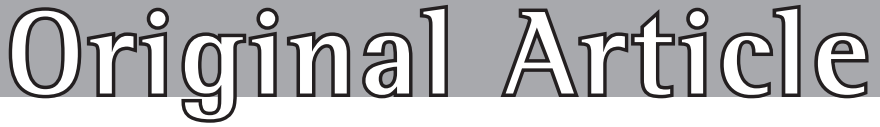

\section{Temporal trend in and spatial distribution of lung cancer mortality in Brazil between 1979 and 2004: magnitude, regional patterns, and gender-related differences*}

\author{
Antonio Fernando Boing', Tiana Fávero Rossi²
}

\begin{abstract}
Objectives: To describe the temporal trend in and spatial distribution of mortality from tracheal, bronchial, and lung cancer in Brazil from 1979 to 2004. Methods: Mortality data by gender and geographic region were obtained from the Mortality Database created by the Ministry of Health in 1975. Demographic data were collected from the national censuses, from population counts, and from population estimates made in non-census years. Mortality rates were standardized according to the direct method, and the trends were analyzed by gender and geographic region using the Prais-Winsten method for generalized linear regression. Results: Lung cancer mortality accounted for approximately $12 \%$ of the overall neoplasia-related mortality during the period. There was a trend toward an increase for both genders and in all regions, except for the male population in the southeast region, whose rates remained steady between 1979 and 2004 . The highest rates were observed in the south and southeast regions. However, the northeast region was the one that presented the greatest increase, followed by the central-west and north regions. In all regions, the increase in mortality rates was higher in women. Conclusions: The increase in lung cancer mortality in Brazil between 1979 and 2004 requires public measures that can minimize exposition to risk factors, mainly tobacco, and allow greater access to health care facilities for diagnosis and treatment.
\end{abstract}

Keywords: Lung neoplasms; Epidemiology; Brazil.

\footnotetext{
* Study carried out in the Public Health Department of the Federal University of Santa Catarina, Florianópolis (SC) Brazil.

1. Professor in the Public Health Department of the Federal University of Santa Catarina, Florianópolis (SC) Brazil.

2. Medical Graduate Student. Federal University of Santa Catarina, Florianópolis (SC) Brazil.

Correspondence to: Antonio Fernando Boing. Universidade Federal de Santa Catarina, Departamento de Saúde Pública, Campus Universitário Florianópolis, CEP 88040-970, SC, Brasil.

Tel 5548 3331-9388. E-mail: boing@ccs.ufsc.br

Submitted: 26 January, 2007. Accepted, after review: 13 February, 2007.
} 


\section{Introduction}

Throughout the 20th century, cancer has been one of the most significant health problems worldwide. It is estimated that there were 24.6 million people living with cancer worldwide in 2002, and that, in the same year, 10.9 million new cases of the disease were reported. In the coming years the expectation is that there will be an increase in the incidence of cancer, and that the number of new cases per year will reach 16 million in 2020.(1) The number of cancer-related deaths is also high. Of a total of 58 million deaths that occurred in 2005, 7.6 million (13\%) were cancer-related, and more than $70 \%$ of those deaths occurred in middle- and low-income countries. ${ }^{(2)}$ In Brazil, cancer has been the second leading cause of death since 2000 , and it is expected that 472,000 new cases will be reported nationwide in 2006. ${ }^{(3,4)}$

Lung cancer is one of the most frequent types of neoplasia in both industrialized and developing countries. In the year 2000 alone, approximately 1.2 million new cases of the disease were reported worldwide, and 75\% of them occurred among men. In the same year, approximately 1 million people died of lung cancer. Of those deaths, $45 \%$ occurred in underdeveloped countries. ${ }^{(6)}$ In Brazil, the National Cancer Institute estimated that there will be 27,170 new lung cancer cases in 2006, of which 17,850 will occur among men and 9320 among women. ${ }^{(6)}$ Those values correspond to an estimated risk of 19 new cases per 100,000 men and 10 new cases per 100,000 women.

In addition to the high incidence and mortality rates, lung cancer presents high lethality. The 5-year survival rate for lung cancer patients is relatively poor, with survival averages being lower than those for other cancers such as colon, breast, and prostate cancer. ${ }^{(7)}$

According to some researchers, ${ }^{(8)}$ the investigation into the historic tendency of health-related events, among which lung cancer mortality can be included, enables a more adequate analysis of health risk control measures, as well as allowing possible changes in their epidemiological structure to be detected. Therefore, the objective of this study was to analyze the temporal trends and geographic distribution of mortality from cancer of the trachea, bronchial cancer, and lung cancer in Brazil from 1979 to 2004.

\section{Methods}

A historical cohort study of cancer of the trachea, bronchial cancer, and lung cancer mortality in Brazil from 1979 to 2004 was conducted. The number of deaths is taken from the Sistema de Informações sobre Mortalidade (SIM, Mortality Database) (3) $^{(3)}$ created by the National Ministry of Health in 1975. The deaths included in the study were caused by malignant cancers of the trachea, bronchioles and lung classified according to the Ninth Revision of the International Classification of Diseases (ICD-9), under code 162 (between 1979 and 1995) and, according to the $1 C D-10$, under the codes $\mathrm{C} 33$ and C34 (between 1996 and 2004). The deaths were classified according to the macroregion of residence (north, northeast, central-west, southeast, or south), gender (male or female) and age bracket (in 5-year brackets until 75 years or older) of the deceased. The decades investigated correspond to the total period for which SIM data on nationwide mortality are available.

Information on the number of inhabitants was obtained from the Brazilian Institute of Geography and Statistics. ${ }^{(9)}$ The population data were collected from the 1980, 1991, and 2000 censuses, from the 1996 population count and, for additional years, from intercensal estimates.

To avoid differences in the population age profile over time and between the analyzed regions that could influence the estimate of the trends, the mortality rates were standardized by sex and age bracket. ${ }^{(10)}$ The rates were adjusted according to the direct standardization method. The male Brazilian population in the year 2000 was taken as the standard.

In the trend analysis, we employed the PraisWinsten method of generalized linear regression, through which the regression parameters, having been controlled by first-order autocorrelation, are estimated. ${ }^{(11)}$ Therefore, in addition to quantifying the rates of annual variations, it was also possible to determine whether the mortality trends were increasing, decreasing, or stable. The respective confidence intervals (95\%) were calculated, and the trend whose regression coefficient was not different from zero ( $p>0.05)$ was considered to be stable. This statistical analysis was carried out using Stata 9 software. The frequency polygons designed were corrected by third-order mobile averages. 


\section{Results}

Between 1979 and 2004, 287,484 deaths resulting from cancer of the trachea, bronchial cancer and lung cancer were registered in Brazil, of which 207,457 occurred in men and 80,027 in women. In 1979, the ratio of deaths by gender was 1 death among women for every 3.3 deaths among men. However, in 2004 that ratio was lower and reached 1:2. The deaths resulting from this type of cancer were responsible for approximately $12 \%$ of the cancer-related mortality in the country during the period of study.

It was found that, between 1979 and 2004, there was an average annual increase of $1.08 \%$ in the mortality rates for cancer of the trachea, bronchial cancer and lung cancer in Brazil (Table 1). Among women, the average annual increase corresponded to $2.44 \%$, with mortality rates varying from 3.04 deaths per 100,000 women in 1979 to 5.37 deaths per 100,000 women in 2004. Among men, the increase in the mortality rates was more modest $(0.77 \%$ per year) $(p<0.001)$. The rate varied from 10.64 deaths per 100,000 men in 1979 to 13.07 deaths per 100,000 men in 2004 . The temporal trends in mortality for both males and females in Brazil are shown in Figure 1.

Throughout the period of study, the south and southeast regions presented the highest lung cancer mortality rates. They corresponded to 14.54 and 9.69 deaths per 100,000 inhabitants, respectively, in 2004 (Figure 2). The central-west region presented mortality rates similar to those of the north and northeast regions at the beginning of the period; however, in 2004, the rate was equal to 9.50 per 100,000 inhabitants, which is quite close to the values reported in the southeast. The lowest rates in 2004 were encountered in the north (6.36 per 100,000 inhabitants) and northeast (4.49 per 100,000 inhabitants) regions. Similar patterns were observed in both males and females.

The trend analysis according to gender and the different regions of the country showed that only men in the southeast had stable mortality rates for cancer of the trachea, bronchial cancer and lung cancer between 1979 and 2004. In the other regions and for both genders, the trend was toward an increase. In the northeast, the highest increase in mortality for the period (3.30\% per year) was identified for both males (2.82\% per year) and females (4.45\% per year). Next, the central-west, north and south regions appear, having showed annual increases of 2.88\%, 1.63\% and 1.17\%, respectively, when both genders were analyzed in conjunction. The increases in the mortality rates were higher among women for all the regions (Table 1).

\section{Discussion}

The analysis of lung cancer mortality trends in Brazil depends on data obtained from the SIM. Therefore, the better the quality of the data available in the SIM is, the more trustworthy are the findings. Another important consideration is that it is known that cancer mortality rates are strongly related to the age profile of the population. However, in the present study, by controlling the effect of the change in age structure through standardization of the coefficients, one can rule out the influence of the increase in life expectancy among Brazilians during the period of study or its regional variation on the calculated rates.

Table 1 - Analysis of cancer of the trachea, bronchial cancer and lung cancer mortality trends according to gender and region of the country - Brazil, 1979-2004.

\begin{tabular}{llcccccc}
\hline Gender & & North & North-East & Central-West & South-East & South & Brazil \\
\hline Male & Trend & $0.91 \%$ & $2.82 \%$ & $2.73 \%$ & $0.13 \%$ & $0.93 \%$ & $0.77 \%$ \\
& $95 \% \mathrm{Cl}$ & $0.42-1.40$ & $2.57-3.08$ & $2.10-3.36$ & $-0.16-0.44$ & $0.49-1.38$ & $0.47-1.07$ \\
& Interpretation & Increase & Increase & Increase & Stable & Increase & Increase \\
\multirow{2}{*}{ Female } & Trend & $3.39 \%$ & $4.45 \%$ & $3.36 \%$ & $1.68 \%$ & $2.57 \%$ & $2.44 \%$ \\
& $95 \% \mathrm{Cl}$ & $2.99-3.79$ & $4.20-4.90$ & $2.56-4.17$ & $1.49-1.86$ & $2.17-2.97$ & $2.27-2.6$ \\
& Interpretation & Increase & Increase & Increase & Increase & Increase & Increase \\
Both & Trend & $1.63 \%$ & $3.30 \%$ & $2.88 \%$ & $0.41 \%$ & $1.17 \%$ & $1.08 \%$ \\
& $95 \% \mathrm{Cl}$ & $1.23-2.03$ & $3.03-3.57$ & $2.20-3.57$ & $0.20-0.63$ & $1.57-1.17$ & $0.86-1.29$ \\
& Interpretation & Increase & Increase & Increase & Increase & Increase & Increase \\
\hline
\end{tabular}




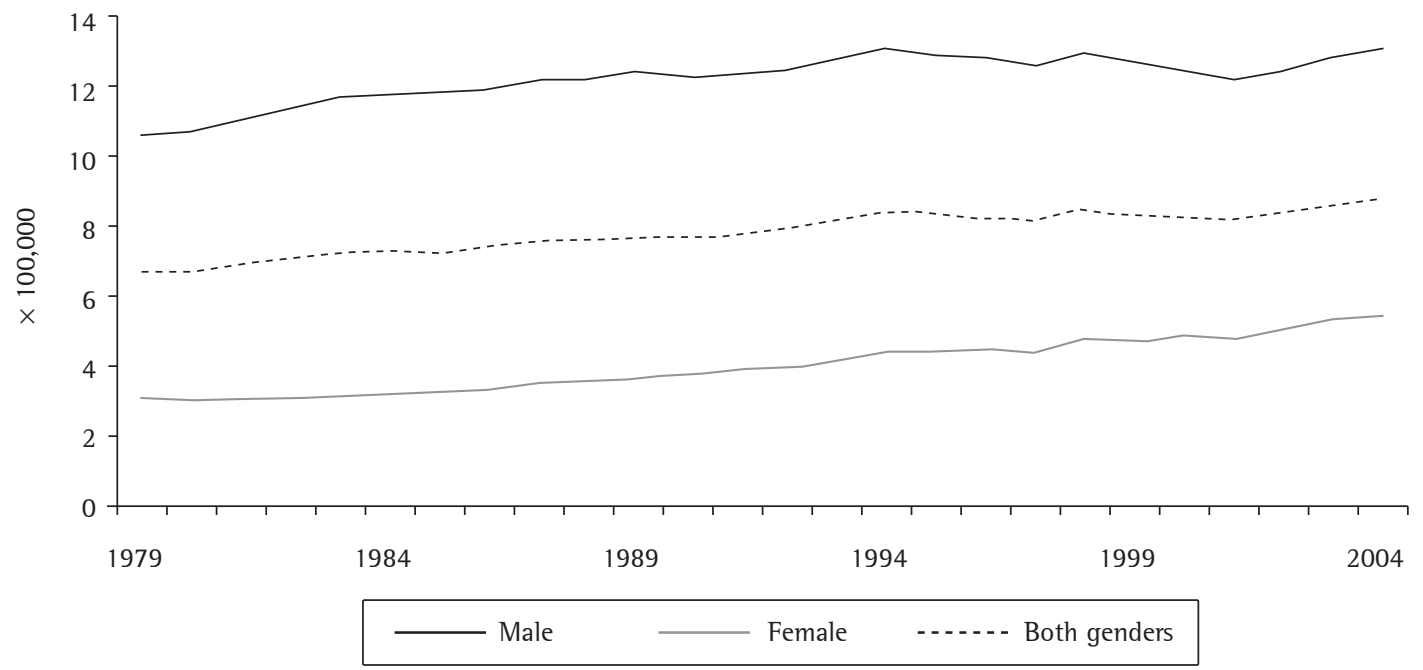

Figure 1 - Historical cohort study of cancer of the trachea, bronchial cancer and lung cancer mortality - Brazil, 19792004.

The results show that the lung cancer mortality rates were higher among men. However, after analyzing the trend, it became clear that there was a marked increase in mortality among women. In recent decades, in some developed countries, lung cancer mortality rates among men have either remained stable or have been decreasing, whereas they have been increasing among women. ${ }^{(12)}$ This fact has been related to a reduction in cigarette consumption among men in those countries in recent decades. The expressive increase of mortality among women identified in the present study can also be related to cigarette consumption and might have a historico-cultural origin. Smoking began worldwide as a predominantly male behavior in industrialized countries and was a rare habit among women until the 1940s. The impact of development and globalization provoked significant changes in female behavior. With their ever greater participation in the labor market, greater purchasing power and greater decision-making power, women began to play a different role in society. In response to this change, the tobacco industry, with the intention of expanding its sales, began marketing campaigns targeted specifically at that population group that, in general, involved athletic models which associated the concepts of beauty, success, intelligence, free speech, power and independence with cigarettes. These strategies transformed the smoking habit into a socially acceptable and even positive behavior that, associated with the easy access to and low cost of the product, allowed and continues to allow for there being an ever greater number of smokers, principally among women and youths in developing countries. Some studies suggest a greater genetic vulnerability to developing lung cancer among women, even when they are exposed to the risk factors in the same manner and intensity as are men. However, the findings in that line of research are still inconclusive, and the possible difference in cross-gender susceptibility remains uncertain, indicating that there is a need for further research on the topic. ${ }^{(12,13)}$

After monitoring the evolution of national lung cancer mortality rates between 1979 and 2004, a real increase was observed in all regions. The male population in the southeast region represents the only exception, presenting stable rates during the period. That same standard was also observed by other researchers ${ }^{(14)}$ who described the temporal trend in cancer-related deaths in Brazil during the 1980s and early 1990s.

In the regional analysis, the highest lung cancer mortality rates were encountered in the south and southeast, which are the regions that present the highest socioeconomic development. However, the northeast, central-west and north regions, respectively, were the ones that presented the highest trends toward an increase. This profile reproduces domestically in the country trends that are similar 

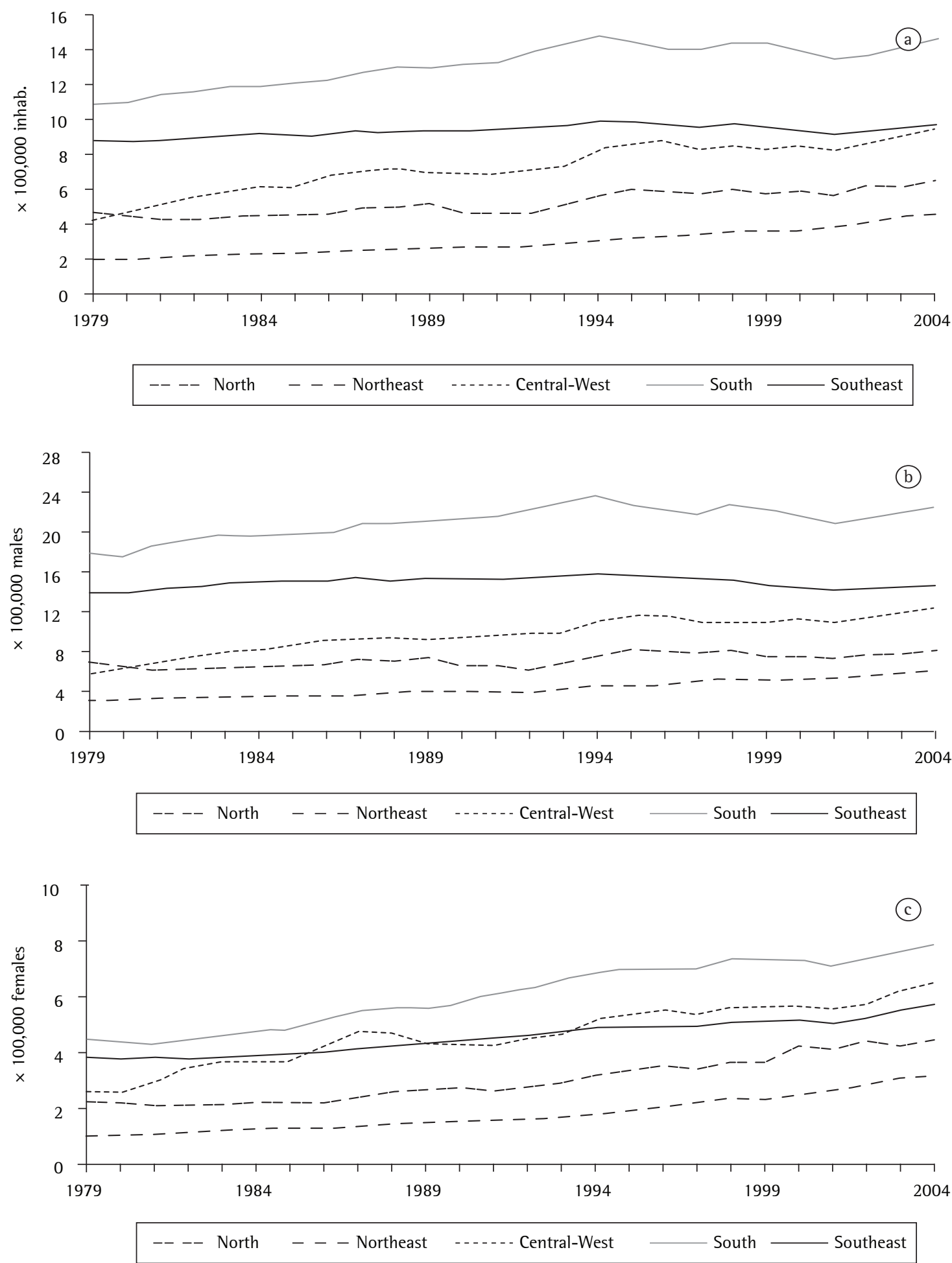

Figure 2 - Historical cohort study of cancer of the trachea, bronchial cancer and lung cancer mortality according to: a) all the inhabitants; b) among men; and c) among women. Macroregions of Brazil, 1979-2004. 
to those observed worldwide: high lung cancer mortality rates are observed in developed countries, whereas in developing countries there is a significantly greater tendency toward an increase in lung cancer mortality.

The central-west stood out by presenting mortality rates similar to those of the north and northeast in the beginning of the study period. However, in recent years, a pattern similar to that seen for the rates in the south and southeast has been observed. It is worthy of note that, in the 1980s and 1990s, the central-west underwent an intense process of urbanization and was the destination of migration, principally of migrants from the south and southeast of the country, which might have contributed to the increase in the rates.

Due to their cultural, demographic, socioeconomic and political heterogeneity, the five regions of the country have populations exposed to different risk and protection factors. They also differ with respect to the quality of death records, the access to health services and the quality of services rendered, as well as regarding diagnostic and therapeutic capacity.

Various studies have shown that lung cancer incidence and mortality reflect, in part, the risk factors to which a given population was previously exposed. ${ }^{(15,16)}$ Smoking, passive exposure to cigarette smoke, atmospheric pollution, diet and occupational exposure (asbestos, radon, arsenic, chromium, nickel, polycyclic hydrocarbons, silica) are examples of significant risk factors for pulmonary carcinogenesis. ${ }^{(17)}$

Among all the aforementioned factors, smoking stands out. It is estimated that the carcinogenic substances in tobacco and their effects on oncogenes are associated with approximately $91.5 \%$ of lung cancer cases in men and $78.5 \%$ of the cases in women. ${ }^{(18)}$ Thus, it is also coherent to associate the regional and temporal differences in lung cancer mortality with the distinct patterns of tobacco consumption in the country. Brazil is the largest exporter of tobacco leaves and the second largest producer of tobacco in the world. Most of the larger plantations are located in the south. ${ }^{(19)}$ The House-to House Survey on Behavioral Risk and Mortality Caused by Nontransmissible Diseases and Insults, ${ }^{(20)}$ conducted in 2002 and 2003 in fifteen Brazilian capitals and the Federal District, reported that the prevalence of smoking in the Brazilian population over 15 years of age was 19\%. Of the eight capitals with the highest prevalence, seven are located in the south and southeast, which are the regions responsible for the highest lung cancer death rates. The highest percentages were observed in Porto Alegre (25\%), Curitiba (22\%) and Florianópolis (21\%), followed by São Paulo (20\%) and Belo Horizonte (20\%). In all of the cities, the initial estimate of the percentage of smokers was greater among men. Despite using distinct methodologies that preclude the possibility of direct comparison, the aforementioned survey and the National Health and Nutrition Survey, ${ }^{(21)}$ which was conducted in 1989, suggest a significant decline in the prevalence of smoking. In southeastern capitals such as Rio de Janeiro and São Paulo, the decline in smoking between 1989 and 2002/2003 was 43.3\% and 33.3\%, respectively, with the highest percentages of smoking cessation having been observed in men. That reduction in smoking observed in Brazil in recent years certainly has had an impact on lung cancer mortality rates. However, the complete effect of that change on consumption will be observed in the mortality rates over the following decades.

The quality of the death records, in addition to being different among the regions of the country, also varied substantially between 1979 and 2004 . During the period of study, there was an improvement in the data produced in the country. ${ }^{(22,23)}$ The mortality rates due to undefined causes presented a sharp decrease in all the regions, particularly in the north, northeast and central-west. In 1998, the south was the region that presented the best quality of information regarding cause of death, since only $7.7 \%$ of deaths were classified according to the Chapter of Undefined Causes, followed by $10 \%$ in the southeast and $10.6 \%$ in the central-west. The north and northeast presented the greatest deficiencies in the registry system. ${ }^{(24)}$ It is possible that part of the increase observed in mortality during the period investigated, as well as the differences in the magnitude of the disease among the regions, was due to improvements in the sources of information and regional differences in the quality of data.

Regarding the use of health services, some authors ${ }^{(25)}$ have reported statistically significant regional differences. According to the authors, data from the 2003 National Household Sample Survey showed that the residents of the south and southeast regions have higher chances of accessing health 
services than do residents of the north (45\% lower chance), northeast (40\% lower chance) and centralwest (23\% lower chance). In addition, despite the fact that access has improved in all the regions between 1998 and 2003, thereby making possible a greater identification of lung cancer cases that in previous years might not have even been reported to health services which, in turn, could have allowed for an early diagnosis of the disease in its initial stages, regional inequality increased. The south and southeast regions, in addition to being home to the greatest number of health professionals per 100,000 inhabitants, have the greatest concentration of health care resources, including important technological equipment for the diagnosis of lung cancer such as computed tomography and magnetic resonance imaging. ${ }^{(23)}$ Progress in lung cancer therapy over the last 20 years has also been modest. Available treatments, especially chemotherapy (with or without radiotherapy), continue to be quite toxic. The investigation of new agents is of great relevance, as is research on gene therapy, although those studies are still in the initial stages. ${ }^{(26)}$

In view of the increasing trend of lung cancer mortality and of the currently great magnitude of deaths as a result of that neoplasm, it must be borne in mind that that disease is a relevant public health problem in Brazil. Given the elevated risk for the disease related to tobacco use, interventions that seek to minimize smoking in the country are absolutely necessary.

By 1993, health care costs arising from smoking-related diseases already resulted in a loss of 200 billion dollars. ${ }^{(27)}$ Non-measurable costs such as the negative impact on the quality of life of patients and the harmful effects of tobacco on the environment should also be considered. Since the clinical treatment of lung cancer can help reduce the number of people with the disease by only approximately $10 \%$ and costs approximately 18 million dollars per year of life gained by the patient, preventive actions focused beyond the individual dimension that seek to meet social, political and economic variables become more logical and feasible.

Bearing in mind that Brazilian cigarettes are among the cheapest in the world, an increase in taxes on the product would be a strategic measure. It is estimated that a $10 \%$ increase in prices of the product would provoke, in middle and low income countries, an $8 \%$ decrease in cigarette consump- tion. ${ }^{(29)}$ The effect might be even stronger if the percentage of taxes collected by the state is utilized for the promotion of anti-smoking campaigns. In addition, other measures as well as actions foreseen in the Framework Convention on Tobacco Control should be implemented or maintained: protecting the population, especially youths, from advertising; regulating and monitoring tobacco products with respect to their composition and emission of pollutants; using tobacco packaging to convincingly inform the population about the real dimension of the risks posed by smoking; limiting the access of youths to tobacco products by controlling both selling mechanisms and the black market; and protecting the population from the risks of passive smoking. ${ }^{(29)}$

\section{References}

1. World Health Organization.Global actions against cancer. WHO, 2005; 1-24p.

2. Wolrd Health Organization.Cancer control: knowledge into action.WHO, 2006; 1-40p.

3. Ministério da Saúde [Homepage on the Internet].Brasília: 2007 [cited 2006 Nov 6].Sistema de Informações sobre Mortalidade.Available from: http://tabnet.datasus.gov.br/ cgi/sim/obtmap.htm

4. Brasil.Ministério da Saúde.Secretaria de Atenção à Saúde. Instituto Nacional de Câncer.Coordenação de Prevenção e Vigilância.Estimativa 2006: incidência de câncer no Brasil. Rio de Janeiro: INCA; 2005.

5. Wolrd Health Organization.National cancer control programs: policies and managerial guidelines.WHO, 2002;1-180p.

6. Ferlay J, Bray F, Pisani P, Parkin DM.Globocan 2000.Cancer incidence, mortality and prevalence worldwide.Lyon: IARC PRESS;2001.

7. Alberg AJ, Samet JM.Epidemiology of lung cancer. Chest.2003;123(1 Suppl):21S-49S.

8. Rouquayrol MZ, Barreto M.Abordagem descritiva em epidemiologia.ln: Rouquayrol MZ, Almeida-Fiho N.Epidemiologia e Saúde.Rio de Janeiro: MEDSI; 2003.p.83-122.

9. Instituto Brasileiro de Geografia e Estatística [Homepage on the Internet].Brasília: IBGE, 2004 [cited 2006 Nov 10]. Available from: http://www.ibge.gov.br.

10. Pagano N, Gauvreau K.Princípios de bioestatística.São Paulo: Thomson Learning; 2000.

11. Antunes JL, Waldman EA.Trends and spatial distribution of deaths of children aged 12-60 months in São Paulo, Brazil, 1980-98.Bull World Health Organ.2002;80(5):391-8.

12. World Health Organization.Gender in lung cancer and smoking research.WHO, 2004;1-43p.

13. Rivera MP, Stover DE.Gender and lung cancer.Clin Chest Med.2004;25(2):391-400.

14. Wünsch Filho V, Moncau JE.Mortalidade por câncer no Brasil 1980-1995: padrões regionais e tendências temporais. Rev Assoc Méd Bras.2002;48(3):250-7. 
Temporal trend in and spatial distribution of lung cancer mortality in Brazil

between 1979 and 2004: magnitude, regional patterns, and gender-related differences

15. Doll R, Hill AB.The mortality of doctors in relation to their smoking habits: a preliminary report.1954. BMJ.2004;26;328(7455):1529-33.

16. Tyczynski JE, Bray F, Parkin DM.Lung cancer in Europe in 2000: epidemiology, prevention, and early detection. Lancet Oncol.2003;4(1):45-55.Erratum in: Lancet Oncol.2003;4(7):396.

17. Bilello KS, Murin S, Matthay RA.Epidemiology, etiology, and prevention of lung cancer.Clin Chest Med.2002;23(1):1-25.

18. Ministério da Saúde.Instituto Nacional de Câncer. Coordenação Nacional de Controle do Tabagismo, Prevenção e Vigilância do Câncer.Falando sobre o Câncer de Pulmão. MS/INCA; 2000.

19. Ministério da Saúde.Instituto Nacional do Câncer.Coordenação de Prevenção e Vigilância.Prevalência de Tabagismo no Brasil - Dados dos inquéritos epidemiológicos em capitais brasileiras.Coordenação de Prevenção e Vigilância/INCA/MS, 2004;1-16p.

20. Ministério da Saúde.Inquérito domiciliar sobre comportamento de risco e morbidade referida de doenças e agravos não transmissiveis.INCA/MS, 2004;1-30p.

21. Ministério da Saúde.Pesquisa Nacional sobre Saúde e Nutrição: Perfil de Crescimento da População Brasileira de 0 a 25 anos.INAN; 1990.
22. Mello Jorge MHP, Gotlieb SLD.As condições de saúde no Brasil: retrospecto de 1979 a 1995.Rio de Janeiro: Fiocruz; 2000.

23. Organização Pan-Americana da Saúde.O perfil do sistema de serviços de saúde Brasil.2a ed.Brasília: OPAS, 2001; 1-23p.

24. Organização Pan-americana de Saúde.lndicadores básicos para a saúde no Brasil: conceitos e aplicações.Brasília: OPAS, 2002; 1-299p.

25. TravassosC,ViacavaF,FernandesC,Almeida CM.Desigualdades geográficas e sociais na utilização de serviços de saúde no Brasil.Ciência Saúde Coletiva.2000;5(1):133- 49.

26. Biesalski HK, Bueno de Mesquita B, Chesson A, Chytil F, Grimble R, Hermus RJ, et al.European Consensus Statement on lung Cancer: risk factors and prevention.Lung Cancer Panel.CA Cancer J Clin.1998;48(3):167-76; discussion 164-6.

27. The World Bank.Curbing the Epidemic: Governments and the Economics of Tobacco Control.Washington D.C.: The World Bank Publication; 1999.

28. World Health Organization.Women and the tobacco epidemic: challenges for the 21st century.WHO, 2001.

29. Ministério da Saúde.Instituto Nacional de Câncer.Falando sobre Tabagismo. MS/INCA, 1998. 